another queen leave the entrance with a similar burden. This led me to examine some twenty nests-all, in fact, that I had time to excavate before I was obliged to proceed with the party. My rather hurried observations showed that about half of the craters had been established by single queens but that the others were each the work of two coöperating queens. One crater actually contained five queens, four deälated and one with intact wings! It appears, therefore, that about 50 per cent. of the colonies of mimicus are pleometrotic in origin. That they probably remain so is indicated by the fact that on former excursions in Arizona I have on several occasions taken more than one deälated queen from a single adult colony of this ant.

The foregoing observation is of interest to the myrmecologist, because the mimicus queens were actively coöperating in the construction of a single nest as if they had been so many workers, whereas in the rare cases of Lasius flavus and brevicornis above cited the consociation of two queens may be interpreted as due to an accidental meeting under the same stone just after the marriage flight. Of course, it is very probable that in all the cases the queens in the same nest were sisters that had met after fecundation, since queens from different maternal nests would hardly work together so harmoniously. Nevertheless, the very high percentage of cases of primary pleometrosis in mimicus points to the existence in this ant of a pronounced tendency for recently fecundated sisters to assemble in pairs or even greater numbers for the purpose of founding and developing a colony in common.

\title{
THE DISTRIBUTION OF THE NOSE FLY AND OTHER SPECIES OF GASTROPHILUS IN THE UNITED STATES. ${ }^{1}$
}

By F. C. Bishopp,

Bureau of Entomology, Dallas, Texas.

The distribution of the species of bot flies in the United States is a question which has been much neglected. Each is of considerable importance to stock raisers and farmers in this country and

\footnotetext{
1 Published by permission of the Chief of the Bureau of Entomology.
} 
it seems strange that more facts regarding their introduction, spread and local and seasonal abundance have not been recorded.

The common horse bot or nit fly, Gastrophilus intestinalis De Geer, on account of its abundance and comparatively slow flight, has been most readily observed and most frequently mentioned in literature. It was undoubtedly introduced into this country many years ago and has become widely spread throughout the United States. We have records of its occurrence in nearly all

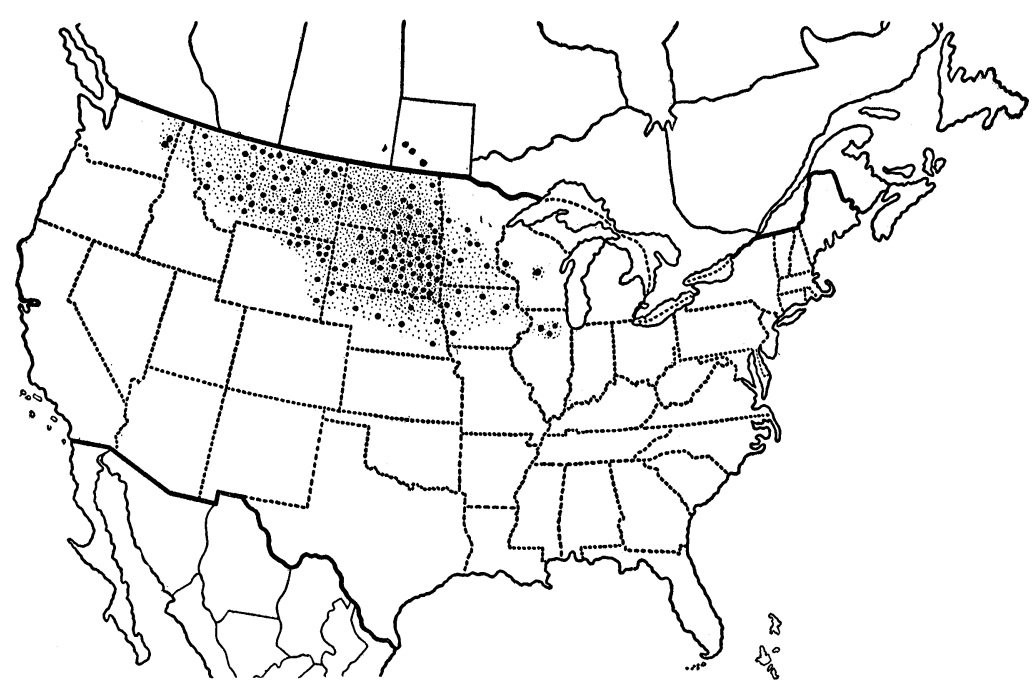

Fig. 1. Map showing the distribution of the nose fly, Gastrophilus homorrhoidalis $\mathbf{L}$. in the United States. The large dots indicate localities where this insect has been reported and the small dots its probable distribution.

parts of the country though it seems to vary much in local abundance. At high elevations it seems to be rare.

The chin fly, G. nasalis L., also appears to be well distributed over the United States. We have rather clear records of its occurrence in practically all states from Texas to North Dakota and from New York to California; also in the western part of Canada. It occurs, no doubt, in the eastern part of Canada, and in the eastern states of the Union.

The nose fly, G. homorrhoidalis L., is undoubtedly the most important economic species of the three when it is present in abun- 
dance, due to the worriment caused by the adult during the period of oviposition.

The distribution of the nose fly was less known than the others until the work of the Bureau of Entomology on this pest was taken up three years ago. The common name which is generally used over the territory where it abounds and the scientific name of one of the other species (G. nasalis) has led to some confusion. It may be said that neither of these names are very appropriate as the eggs of G. homorrhoidalis are laid on the lips and those of G. nasalis under the jaws. The last named species has received the vernacular names of "chin fly" or "throat bot fly." The employment of the common name "nose fly" for the former species seems to be justified by usage among farmers and the name "throat bot fly" is preferred for the latter on account of the egg-laying habits of the female and the habit of the larvæ of this species of attaching occasionally at least in the œesophagus.

The early history of the occurrence of this species in the United States seems to be clouded. Lugger, in his second Minnesota Report (p. 242), records it positively from that state. The actual specimen upon which the statement is based is not in existence, however, according to Prof. C. W. Howard. Some seem to have accredited the species to Kentucky, based on Professor Garman's statements in the Kentucky Experiment Station Report of 1894, but he does not record the species from that state, and informs me he has never seen the fly there.

During the summer of 1914 the writer made preliminary inquiry into the distribution, history of spread, and the injuriousness of the nose fly in the north-central states, where it had been reported to the Bureau as a serious pest of horses. At that time the insect appeared to exist throughout the greater part of North and South Dakota, eastern Montana, and possibly to occur in limited numbers in western Minnesota. No effort was made to determine the exact limits of distribution. It is evident, however, that the species has been spreading southward and eastward, as shown by statements of numerous farmers more recently interrogated in different sections. While there is some disparity the statements agreed remarkably well as to the time of first appearance in a given community. In 1914 it appeared that the fly had become established south of the center of South Dakota only within the 
preceding four or five years. In working northward and westward the dates set by farmers as the time of first appearance became earlier until Minot, N. D., was reached where a rather authoritative record was secured of the occurrence of the fly eighteen years before (1896).

During the spring of 1915 and $1916 \mathrm{Mr}$. W. E. Dove and the writer made further inquiry into the distribution of this insect in parts of South Dakota and Minnesota, and Mr. Dove was located in this region and made further inquiry regarding the history of the spread of the insect during the summers of 1915 and 1916. His work largely substantiated the earlier findings.

To supplement personal observations and questioning, a large number of letters of inquiry were sent to farmers and horse breeders in the region from Indiana to Washington, and Kansas to Canada. About 350 replies were received. One correspondent each in Colorado, Idaho, Utah and Oregon, and three in Washington replied that the nose fly is present, but there is reason to believe they were mistaken in the identity of the insect, except possibly two in eastern Washington. ${ }^{1}$ All reports from Indiana, Kansas and Missouri were negative. Three affirmative ones were received from Illinois and two from Wisconsin. ${ }^{1}$ While neither was corroborated with specimens it is practically certain that infestations, possibly more or less local, occur in these states. Montana and North and South Dakota are generally infested at this time and central western Minnesota, northern Nebraska and northeast Wyoming undoubtedly so. It appears from replies and personal examinations that the insect is more or less scattered over Iowa, but probably not numerous except in the northwest part.

In Canada we have learned through correspondents of the presence of the nose fly in southern Manitoba and Saskatchewan.

A very interesting discussion regarding the occurrence of the nose fly in Canada appeared in the Proceedings of the Entomological Society of Ontario for 1915. Professor Lochhead there presents extracts from some correspondence from men in western Canada. It is my opinion that these correspondents, except one from Ontario, refer especially to $G$. homorrhoidalis although one sent in specimens of $G$. nasalis, which is much more easily caught.

\footnotetext{
1Since this article was submitted for publication the localities in Wisconsin and Washington have been visited. The nose fly is well established in western Wisconsin but its presence in central Wisconsin and eastern Washington could not be verified.
} 
This apparently led to some confusion as to the species concerned and the use of the term "nose fly" led to further confusion. It should be remembered that this vernacular name is applied with few exceptions to $G$. hoomorrhoidalis by horse breeders and farmers. These men write of the presence of the insect in Alberta as well as Manitoba and Saskatchewan, and it probably occurs still farther west.

The dates of first appearance in the different sections as reported by correspondents agree quite well with what has been found by inquiry by Mr. Dove and the writer. The earliest date given was 1883, by a correspondent in western North Dakota, and a correspondent in central Montana (Fergus County) states that they were there in 1898, and another slightly farther west in Montana gives 1890 as the date of appearance. Wyoming and Minnesota seem to have been invaded during the last seven years, Nebraska within the past six years, Iowa about five years ago, and the other states more recently.

Just why G. homorrhoidalis did not come into prominence as a pest of horses years ago it is difficult to tell. It seems almost certain that the species was brought into this country at an early date with shipments of horses from Europe. Failure to establish itself may have been due to conditions surrounding the imported animals after arrival here; such as adverse climatic conditions. It is possible that climate may have a marked influence on the perpetuation of the species in any region and that it will not thrive in the more humid area east of the present area of great abundance in the Dakotas. It is also barely possible that the species may have been present in parts of this country years ago and then became extinct or nearly so, but this is hardly plausible. Certainly our investigations indicate a comparatively recent establishment of the insect in the United States, and that the point of first establishment was in western North Dakota or eastern Montana, or possibly in southern Saskatchewan.

The habits of the insect indicate that its dissemination is largely brought about by the movement of horses. The long time which the larvæ spend within the host and the rather extended period during which they normally leave the animal add to the danger of spread by shipping or driving horses from infested to uninfested territory. The great number of horses recently shipped from in- 
fested regions to concentrating points from which they were transshipped to Europe for military purposes may have resulted in the establishment of other foci of infestation not now known. Increased activity at this time in the shipment of horses from the infested territory for use in our own cavalry and for agricultural purposes will no doubt give every opportunity for the insect to become widely established if some natural agencies do not prevent or steps are not taken to destroy the bots before horses are shipped.

The accompanying map shows the probable present distribution of the species in the United States, and indicates the points where its presence has been observed by us or recorded by correspondents. The comparatively small number of large dots in North Dakota is explained by fewer circulars being sent there rather than by a smaller number of nose flies.

\section{PRELIMINARY EXPERIMENTS WITH SODIUM FLU- ORIDE AND OTHER INSECTICIDES AGAINST BITING AND SUCKING LICE.}

By F. C. Bishopp and H. P. Wood,

Bureau of Entomology, U. S. Department of Agriculture.

The very satisfactory results secured by the authors with the use of sodium fluoride against various species of biting lice (Mallophaga) on chickens and other domestic fowls ${ }^{1}$ naturally has led to inquiry from many sources as to the effect of this compound on lice of cattle, horses, and other domestic animals. So it is thought advisable at this time to publish a few preliminary notes on the results of the use of this material and other insecticides against several species of Mallophaga and sucking lice on such hosts. A few experiments carried out during 1910 and 1912 indicated that the standard arsenical dip usually known as the B. A. I. formula (8 lbs. white arsenic, 24 lbs. sal soda, 1 gal. pine tar, to 500 gals. water) is a very effective insecticide against both the Mallophaga and Anoplura. In these tests it was found that one thorough spraying or dipping of cattle quite heavily infested with biting lice (Trichodectes scalaris Nitzsch), and the short-nosed ox louse (Homatopinus eurysternus Nitzsch) completely destroyed them in

1 See Farmers' Bulletin No. 801. 

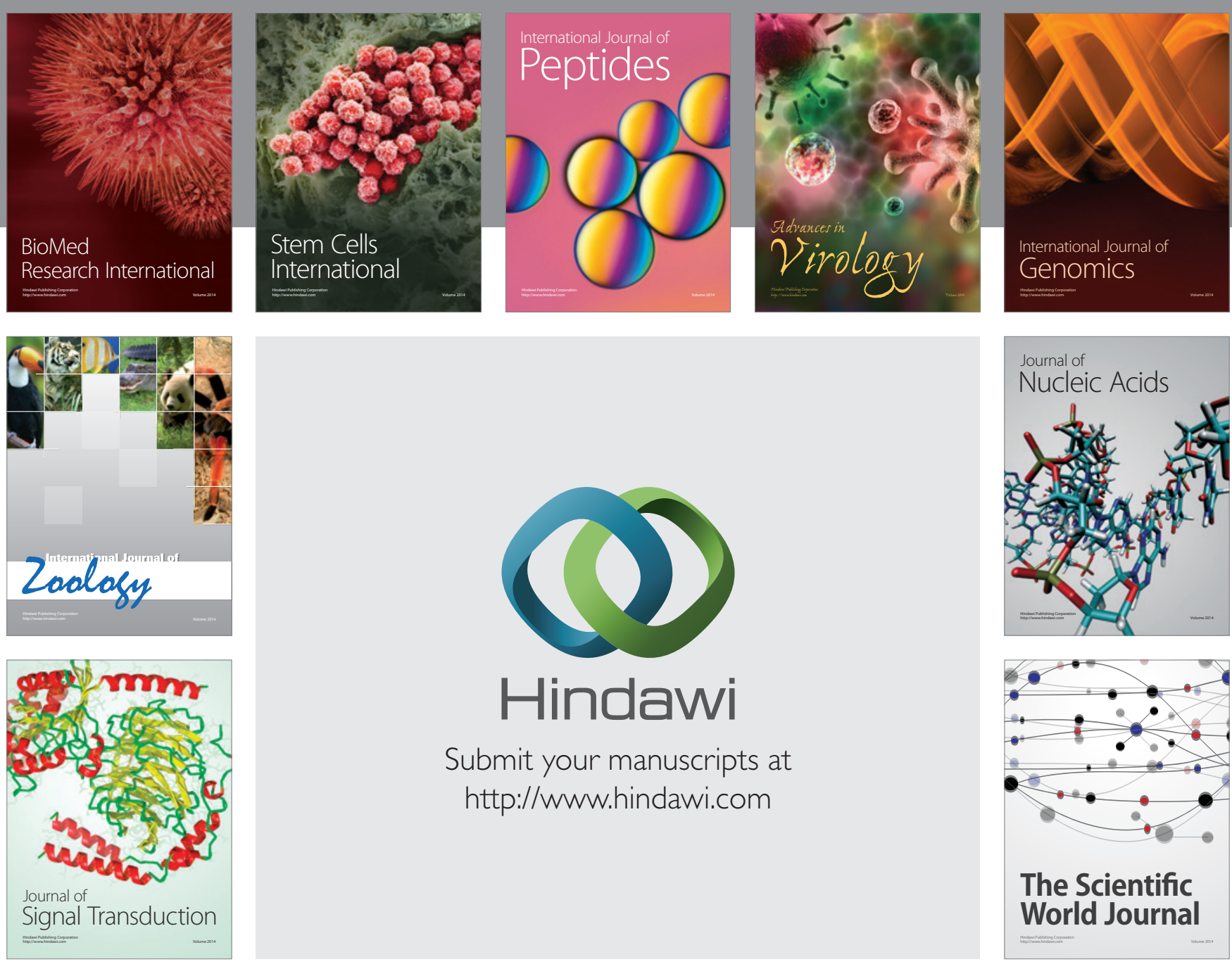

Submit your manuscripts at

http://www.hindawi.com
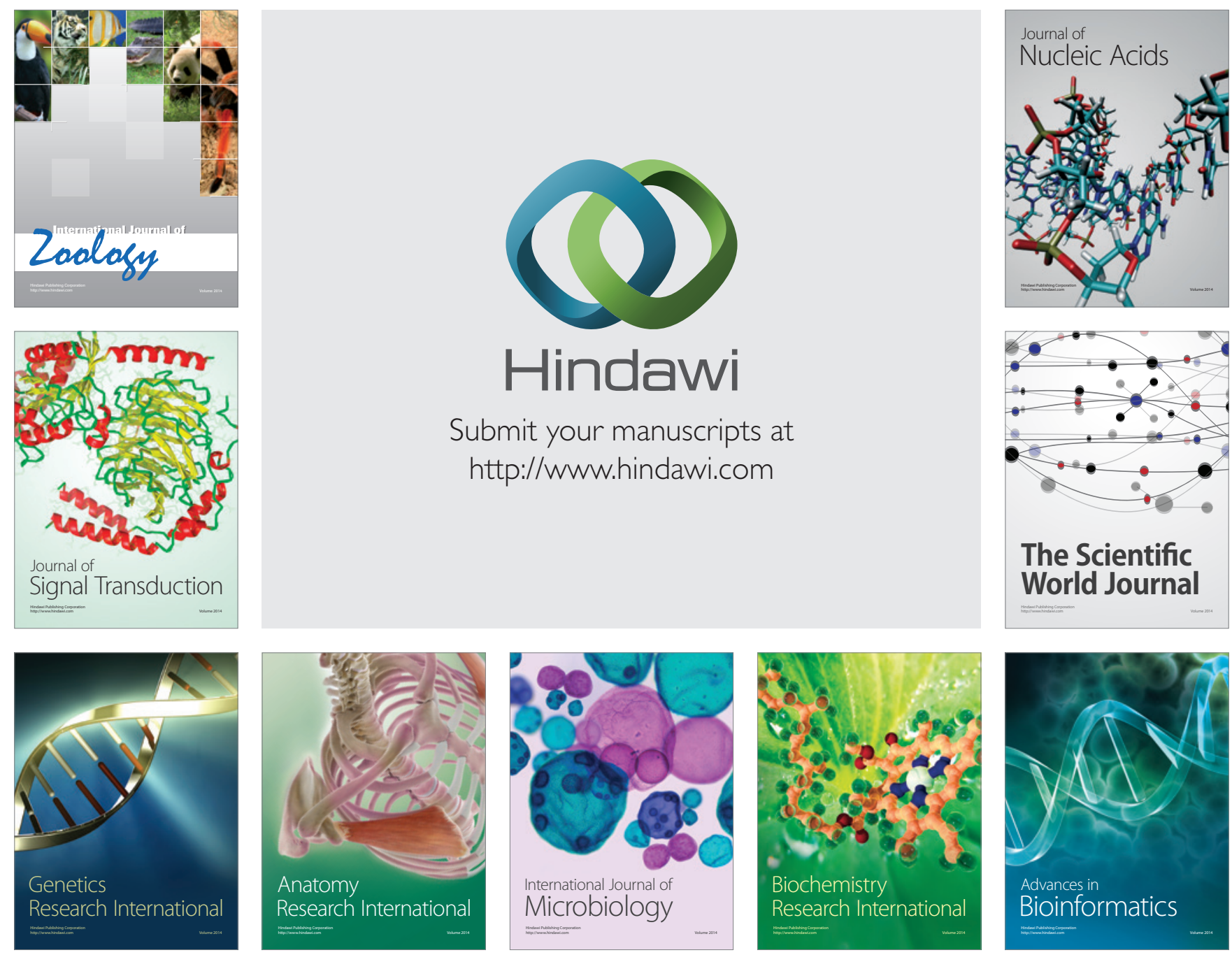

The Scientific World Journal
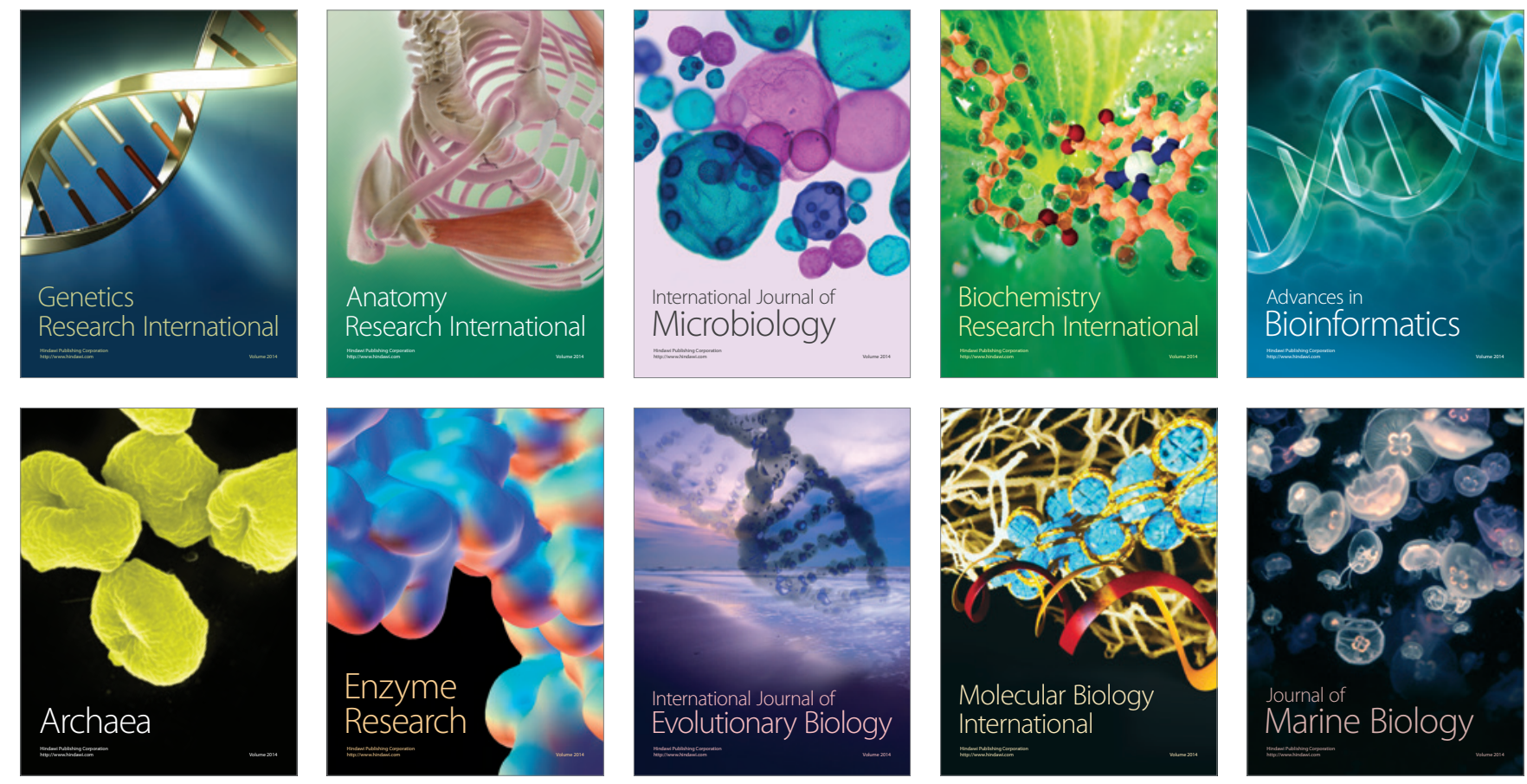